\title{
Positive Behavioral Interventions and Supports in High Schools: A Case Study from New Hampshire
}

\author{
Hank Bohanon \\ Loyola University Chicago, hbohano@luc.edu \\ JoAnne Malloy \\ University of New Hampshire - Main Campus \\ Kathy Francoeur
}

Follow this and additional works at: https://ecommons.luc.edu/education_facpubs

Part of the Education Commons

\section{Recommended Citation}

Bohanon, Hank; Malloy, JoAnne; and Francoeur, Kathy. Positive Behavioral Interventions and Supports in High Schools: A Case Study from New Hampshire. Journal of Educational and Psychological Consultation, , : , 2017. Retrieved from Loyola eCommons, Education: School of Education Faculty Publications and Other Works, http://dx.doi.org/10.1080/10474412.2017.1385398

This Article is brought to you for free and open access by the Faculty Publications and Other Works by Department at Loyola eCommons. It has been accepted for inclusion in Education: School of Education Faculty Publications and Other Works by an authorized administrator of Loyola eCommons. For more information, please contact ecommons@luc.edu.

\section{c) (†) $\ominus$}

This work is licensed under a Creative Commons Attribution-Noncommercial-No Derivative Works 3.0 License. (C) Taylor \& Francis 2017 


\begin{abstract}
The quality of a school's social environment is critically related to student outcomes, including academic performance, attendance, student behavior, and high school completion rates. New Hampshire engaged in a dropout prevention initiative between 2006 and 2012 that focused on implementation of the multi-tiered Positive Behavioral Interventions and Supports (PBIS) framework combined with an intensive, student-driven school-to-adult life transition intervention for the highest-need youth. This paper presents a case study of how one high school in the New Hampshire dropout prevention project implemented PBIS at all three tiers of support: schoolwide, targeted, and intensive. The case study includes a description of practices implemented by the school, school and student level outcomes pre- and post-implementation, and successes and challenges experienced by the school staff. The discussion ends with recommendations for practice and research of PBIS implementation in high schools.
\end{abstract}


PBIS IN HIGH SCHOOLS

Positive Behavioral Interventions and Supports in High Schools: A Case Study from New Hampshire

There is a critical link between social and emotional health and a child's readiness and ability to learn (Zins, Weissberg, Wang, \& Walberg, 2004). While school reform has been a national priority for nearly three decades, concerns remain among policy makers and educators that our education system is not adequately meeting the social, emotional, and academic needs of all students (American Civil Liberties Union, 2008; Brownstein, 2009; Losen \& Gilespie, 2012; Losen \& Skiba, 2010). Students with emotional and behavioral disorders (EBD) and students from ethnically and racially diverse populations are particularly vulnerable. They are victims of an achievement gap, characterized by disproportionate rates of school failure and poor adult life outcomes (Losen, Hodson, Keith, Morrison, \& Belway, 2015; Newman, Wagner, Cameto, \& Knokey, 2009). To address this gap there has recently been focus on personalizing the school environment and meeting the diverse social and emotional needs of all students by implementing policies, routines, and evidence-based instructional practices using a positive behavior supports framework (Duncan, 2010; Murphey, et al., 2014; U.S. Department of Education, 2012). Specific to high schools, there has also been a movement towards teaching students "non-cognitive” skills that will enable them to be successful in the $21^{\text {st }}$ Century economy, such as the ability to work in teams, persistence when confronted with difficult tasks, and how to apply problem-solving strategies to successfully address complex situations (Farrington, et al., 2012).

\section{Positive Behavioral Interventions and Supports: Addressing the Needs of Every Student}

Students perform better academically and engage in fewer problem behaviors in school settings where there are clear expectations and where they feel connected and cared for 
PBIS IN HIGH SCHOOLS

(Flannery, Sugai, \& Anderson, 2009; Way, Reddy, \& Rhodes, 2007). An effective approach to creating predictable, safer, and caring school environments is the multi-tiered model of Positive Behavioral Interventions and Supports (PBIS) (Horner \& Sugai, 2005; McIntosh, Filter, Bennett, Ryan, \& Sugai, 2010; Sugai, 2002). The PBIS framework includes a universal or schoolwide (tier 1) system of evidence-based behavioral practices for all students, a targeted (tier 2) system of practices for youth who need additional behavior support, and a tertiary (tier 3) system of intensive, individualized interventions for a relatively discreet percentage (1-5\%) of students with the greatest behavioral needs.

The key features of the PBIS framework (Kincaid et al., 2016) include: (a) universal and commonly-understood schoolwide behavior expectations to promote a positive school climate, (b) shared leadership reflected by organization in representative implementation teams, (c) databased decision making, (d) implementation of research-based practices based on the science of human behavior change, (e) support for staff through job-embedded professional development, and, (f) carefully planned implementation cycles with continuous monitoring and improvement of outcomes (Fixsen, Blasé, Timbers, \& Wolf, 2007; McIntosh, et al., 2010; Sugai, 2002). This multi-tiered structure is developed within a culturally specific context and directed by diverse and representative implementation teams at each level. The PBIS implementation or systems team membership should reflect the values and cultural profile of the community, and, when implemented as intended, the teams design and support implementation of practices and interventions that are relevant to members of that community (Vincent, Randall, Cartledge, Tobin, \& Swain-Bradway, 2011).

The major practices that are implemented at tier 1 within the PBIS framework include universal screening, articulation of valued social and behavioral skills that are consistently taught 


\section{PBIS IN HIGH SCHOOLS}

and reinforced, use of data to monitor progress and outcomes, and differentiated academic instruction. Tier 2 practices are typically characterized by the implementation of small group, research-based skill instruction for students who are experiencing difficulties meeting the school's universal behavior expectations. Tier 3 practices are person-centered and individualized, such as student-centered wraparound planning, student-centered teams, and individualized function-based behavior support (Skiba \& Peterson, 2000). The National Technical Assistance Center for Positive Behavior Interventions and Supports (PBIS TA Center) reports that over 21,000 schools are implementing PBIS in all 50 states, however, only 13\% of those are high schools (Horner, 2014).

\section{Outcome Research of PBIS Implementation}

School-wide PBIS (SWPBIS) implementation is related to improved academic achievement and reductions in problem behaviors (Bradshaw, Mitchell, \& Leaf, 2010; Bradshaw, Reinke, Brown, Bevans, \& Leaf, 2008; Childs, Kincaid, George, \& Gage, 2016; Freeman, et al., 2016; Horner, Sugai, Todd, \& Lewis-Palmer, 2005; Lassen, Steele, \& Sailor, 2006; McIntosh, Chard, Boland, \& Horner, 2006; Sadler \& Sugai, 2009). Similarly, studies specific to high schools have demonstrated an association between SWPBIS implementation and increased student attendance and reductions in problem behavior (Flannery, Fenning, Kato, \& McIntosh, 2014; Freeman, et al. 2016). The majority of SWPBIS implementation and research has been at the elementary level, however (Horner, Sugai, \& Anderson, 2010; Horner, et al. 2009). While the primary features of PBIS implementation are the same regardless of instructional level and setting, implementation in high schools is complicated by contextual factors such as the focus on graduation requirements, supporting the transition from high school to post-school education and employment, and the unique social and emotional needs of 
PBIS IN HIGH SCHOOLS

adolescents (Flannery, Frank, Kato, Doren, \& Fenning, 2013). Further, few studies have focused on the effects of PBIS implementation at all 3 tiers in schools at any instructional level (Stewart, Benner, Martella, \& Marchand-Martella, 2007). Understanding that the primary student variables that are associated with high school completion include attendance, behavior, and academic performance (Balfanz, Herzog, \& Mac Iver, 2007; Hammond, Linton, Smink, \& Drew, 2007), there is a need for in-depth research about how PBIS implementation and evidence-based social/emotional skills development can be implemented in high schools and improve student outcomes as they move into adulthood.

\section{Training and Consultation that Supports PBIS Implementation}

One of the primary features of PBIS implementation is that decisions about implementation of research-based practices are made by representative school-based teams. PBIS teams focus on installing the systems that enable the implementation of evidence-informed practices. Typically, each school develops a PBIS leadership team focused on SWPBIS implementation for all students, and a separate team focused on implementation of practices for students who need additional behavior or social support. All PBIS teams use data to identify the extent of and specific student behavior needs, identify evidence-informed practices that are most likely to meet the specified needs, identify the needs of the staff to implement the practices, obtain training as required by staff, and use data to monitor progress as interventions are delivered. PBIS team members typically require intensive training and consultation from an experienced PBIS consultant to learn how to function well as a PBIS team, including the foundational elements of PBIS implementation, how to use data to make decisions, and how to install new practices.

Foundational training and external consultation, defined as "a process that facilitates 


\section{PBIS IN HIGH SCHOOLS}

problem solving for individuals, groups, and organizations,” are critical features for the successful implementation of any new framework or practice (Fixsen, Naoom, Blase, Friedman, \& Wallace, 2005; Journal of Educational and Psychological Consultation, 2017). Within a PBIS framework, external consultants, often referred to as PBIS coaches, guide the school teams through the stages and elements of the multi-tiered model and help school leaders and staff to address implementation issues such as: (a) the complexity of the implementation process, (b) using data for decision making, (c) the role of interdisciplinary leadership and collaboration, and (d) provide technical assistance (Forman \& Crystal, 2015). PBIS coaches also address implementation barriers such as a lack staff buy-in (Bohanon \& Wu, 2014; Lohrmann, Martin, \& Patil, 2013) and resistance to implementing PBIS practices that may result from misunderstandings about the approach, existing problems with school climate, and opposing philosophical ideology (Tyre \& Feuerborn, 2016). External PBIS coaches provide support to teams and administrators so they can see the relevance of and appropriately apply the PBIS strategies within their school's context and culture. This type of external coaching is a critical element to achieve fidelity of PBIS implementation (OSEP, 2015).

External PBIS coaches also collaborate with school administrators and specialists, such as school psychologists, to develop the capacity to support implementation within the school. Administrators and school specialists contribute unique skills and have access to resources that can be critical to the school's implementation effort (Eagle, Dowd-Eagle, Snyder, Andrew, Snyder, Holtzman, 2015). The PBIS coach and leaders within the school are often required to address cultural barriers such as how to work across professional silos and roles in order to collaborate as a multi-disciplinary team (e.g., special education teachers, general education teachers, school administrators, school counselors, mental health specialists). To address this 
PBIS IN HIGH SCHOOLS

problem, the PBIS coach may work with the school implementation teams to identify goals that are relevant to each staff members' responsibilities and identify outcomes and data points that are important to everyone (Bohanon, Gilman, Parker, Amell, \& Sortino, 2016).

\section{The Unique Needs of Adolescents}

Adolescence is characterized by physical, emotional, cognitive, and social developmental changes, including significant development in areas of the brain that control problem solving and self-regulation. For adolescents with emotional and behavioral challenges, successfully navigating these developmental changes may be especially difficult. Adolescents with emotional and behavioral challenges often experience difficulty forming positive relationships with peers and adults, experience education disruptions, and have cognitive impairments related to stress and anxiety (Stolbach, 2007). These difficulties experienced by youth with emotional and behavioral challenges are reflected in their poor school outcomes, including the highest dropout rates of any sub-group, greater likelihood to be disengaged from school, disproportionally high rates of school discipline referrals, and high placement rates in alternative classroom and schools (Newman et al., 2011; Wagner \& Cameto, 2004; Wagner, Kutash, Duchnowski, Epstein, \& Sumi, 2005). There is a strong correlation between poor attendance, class failure rates, behavior problems in school and risk of high school dropout (Balfanz, Herzog, \& Mac Iver, 2007). The basic features of PBIS, including a focus on positive social/emotional skill development and reinforcement for demonstrating pro-social behaviors, are aligned with recommended approaches to meet the educational and social/emotional needs of all developing adolescents, including those with emotional and behavioral challenges (Carter, Lane, Pierson, \& Glaeser, 2006; U.S. Department of Education, 2016; Wagner \& Davis, 2006).

While a majority of the schools that have implemented PBIS nationally are at the 


\section{PBIS IN HIGH SCHOOLS}

elementary level, there is promising evidence that PBIS implementation can also improve student outcomes at the high school level (Bohanon, 2015; Bohanon \& Wu, 2014; Bradshaw, Pas, Debnam, \& Johnson, 2015; Flannery et al., 2014); Flannery, Guest, \& Horner, 2010; Freeman et al., 2016; Lane, Wehby, Robertson, \& Rogers, 2007). Despite this emerging work, there is a need for examples of how to implement the PBIS multi-tiered framework in the high school context, including how to promote social values that are contextually and developmentally relevant to the unique needs of adolescents, how to incorporate the developmental tasks of the transition from school to career, and how to address the challenges of implementation in the secondary school environment.

\section{Current Study}

The purpose of this case study was to describe the implementation and outcomes experienced by one high school that fully implemented the multi-tiered PBIS framework and practices at all three tiers: tier 1 , targeted, and intensive levels. The study includes a description of practices implemented by the school, and school and student level outcomes pre- and postimplementation, including changes in rates of problem behavior, attendance, dropout rates and academic performance. This study took place between 2006 and 2012 during implementation of a series of federally- and state-funded dropout prevention initiatives led by the New Hampshire Department of Education called Achievement in Dropout Prevention and Excellence (APEX). The high schools in the APEX projects were chosen because they had higher-than-state-average dropout rates. The APEX project combined the multi-tiered PBIS framework with RENEW (Rehabilitation for Empowerment, Natural supports, Education and Work), an evidenceinformed tertiary-level intervention designed to address the needs of transition age youth with emotional and behavioral challenges (Malloy, Drake, Cloutier, \& Couture, 2012). The logic for 
PBIS IN HIGH SCHOOLS

the APEX approach was that overall student engagement will improve and dropout rates will fall when the high school creates a consistent, predictable, and positive school culture, and when there is a continuum of developmentally-appropriate interventions matched to the needs of students with significant challenges (Bradshaw, Waasdorp, Debnam, \& Johnson, 2014; Debnam, Pas, \& Bradshaw, 2012; Pellerin, 2005; Stewart, 2003).

Using a case study format (Scott, 2001), this study profiles implementation and outcomes for one high school that participated in the APEX initiative. The Institute on Disability (IOD) at the University of New Hampshire (UNH) was contracted to administer the APEX initiative, providing training and consultation to the fifteen high schools that implemented the APEX framework. The IOD staff had over fifteen years of experience working with youth with emotional and behavioral challenges, and are the developers of the RENEW model. Figure 1 illustrates the continuum of supports included in the APEX initiative.

$<$ Insert Figure 1 here $>$

The research questions for this case study included: (RQ1) What was the fidelity of implementation of PBIS at tier 1, tier 2, and tier 3? (RQ2) What were the pre- and postimplementation outcomes at tier 1 as measured by student office discipline referrals (ODRs), annual event dropout rate, out-of-school suspension rates, and in school suspension rates? (RQ3) What were the student outcomes pre- and post- intervention at for students who received tier 2 interventions as measured by ODRs, suspensions, and unexcused absences?, and, (RQ4) What were the student outcomes pre- and post-intervention for students who received tier 3 interventions as measured by ODRs, out-of-school suspensions, unexcused absences, credit hours earned per in-school suspensions, Grade Point Average (GPA), and dropout?

\section{Method}


PBIS IN HIGH SCHOOLS

\section{Participants and Setting}

Fifteen high schools participated in the three APEX projects, impacting over 11,000

students. This case study took place in one of the project's high schools in a small city in eastern New Hampshire. The high school was chosen for the project in 2006 based upon its higher-thanstate-average dropout rate and interest in participating. The high school and community were experiencing an increasing trend in the number of students from lower socio-economic (SES) families and students from ethnically and racially diverse backgrounds. The school, a large, brick structure built in the early 1900s, was being publicly criticized because it had the highest annual event dropout rate of any school in the state (8.2\%), and public support for the school was waning. Teacher salaries were some of the lowest in the state, and the school's staff turnover rates were as high as $30 \%$ annually.

This high school has maintained an enrollment of between 570 and 610 students per year since the 2006-07 project baseline year. In 2006, the student population was 2.8\% African American, 2.9\% Hispanic, 2.6\% Asian American, 0\% American Indian/Alaskan, and 91\% White (New Hampshire Department of Education, 2013). Median income in the city was 20\% lower than the New Hampshire average, and the school's special education rate was nearly 20\%, far higher than the average across all New Hampshire school districts. The high school was failing the state's benchmarks for Adequate Yearly Progress (AYP) for dropout rates during the baseline year (New Hampshire Department of Education, 2006).

The study included two cohorts of students who received tier 2 services. The first cohort included eighteen students who received brief Functional Behavioral Assessment (FBA) and individualized Behavioral Support Plans (BSP). Of the eighteen students receiving the brief BSP, seven (39\%) were eligible for special education services, eleven (56\%) were females and eight 
PBIS IN HIGH SCHOOLS

(44\%) were males. The second cohort included thirteen students who received Check In/Check Out (CICO) in small groups. Of these students, seven (53\%) were eligible for special education services, and seven (53\%) were male. Family members were given written notification and gave passive permission for the school to provide behavior supports to their children. The school did not have the capacity to serve every student who needed tier 2 FBA/BSP or CICO supports. A decision-making process was used to identify students who were already receiving less formal interventions to exclude them from the study.

The study also includes data from students who received the RENEW intervention over a period of 6 years, for a total of 25 students. Written consents were obtained from their parents or legal guardians. Of the 25 students, twelve (48\%) were eligible for special education services, 22 (88\%) were White, one was mixed race Hispanic/African American (4\%), one was Hispanic (4\%), one was African American (4\%), and 18 (72\%) were male.

\section{Training}

Staff from the IOD provided approximately one day per week of training and consultation support to school staff and administrators. Large group training in PBIS universal and targeted systems and practices were provided by the New Hampshire Center for Effective Behavioral Interventions and Supports (NH-CEBIS) to members of the school's leadership and targeted intervention teams during the 2007-08 school year. RENEW training and consultation were provided by IOD staff according to the RENEW training protocols (Malloy et al., 2012), including two full-day trainings off site, and twice-monthly modeling and coaching sessions for each facilitator.

Tier 1 Implementation. Implementation of the APEX initiative in the case study high school was consistent with the multi-tiered PBIS framework at all three tiers (May, et al., 2006; 
PBIS IN HIGH SCHOOLS

OSEP, 2015). During the fall of 2006, 96\% of the faculty voted to adopt PBIS after a half-day orientation to the project and the PBIS model. Initial buy-in from the faculty was required before implementation of PBIS could continue. Shortly after the vote, the school formed a tier 1 (universal leadership) team that included general education teachers, a school counselor, a special educator, a student, and the assistant principal. A math teacher volunteered to take the lead as the in-school PBIS coach and received PBIS universal team training and coaching from the IOD staff. During the spring of 2007, the tier 1 team proceeded to put the foundations for schoolwide PBIS in place, including: (a) the development of a diverse and representative tier 1 leadership team that received training in PBIS implementation, (b) the designation of clearly stated roles and responsibilities for team members, including the team leader or “coach” and external training, (c) the development of clearly stated and consistent behavioral expectations, (d) training for all school staff in positive approaches to intervention rather than relying on punishment alone, (e) the development of guidelines and tools for all school staff to use in response to problem behavior, and, (f) installation of the School-Wide Information System (SWIS) and training in a data-based decision making system in order to enhance early identification and enhance effective problem solving (Sugai, et al., 2010).

With coaching from the university staff, the leadership team became increasingly proficient in data-based decision making. For example, the data showed that the primary student behavior problems were "disrespect" and "late to class" during the fall of 2007. Prior to the intervention, the high school had over twice as many office referrals per day compared to a national data set (ECS, 2010). In February 2008, given the extent of the discipline problems (an average of three ODRs per day for disrespect), the team decided to implement an intervention on disrespect. The leadership team designed skits that were enacted by students and teachers in each 


\section{PBIS IN HIGH SCHOOLS}

class. The team also developed an acknowledgment process using a ticket system as a tangible reinforcement. Students elected a "respect student of the week" from each class. All the names of students of the week were put into a drawing for a weekly “secret prize.” Throughout the project period, the tier 1 Leadership Team identified areas where behavior problems were of particular concern and designed similar interventions.

Tier 2 Implementation. After six months of tier 1 team development, the IOD staff assisted the school to convert a pre-existing student assistance team into a tier 2/3 team responsible for identifying students who needed additional behavior support, social/emotional skill development, and designing and implementing tier 2 small group interventions. The tier 2/3 team was also responsible for identifying students with the most significant emotional and behavioral challenges and who needed individualized tier 3 supports. The tier 2/3 team identified a school staff member to be the building level coach, received ongoing technical support and training from the IOD, created tier 2 entry/exit criteria based upon screening data, used databased decision-making to monitor student progress, and designed and supported the implementation of two evidence-based practices: brief BSPs (Crone, Hawken, \& Horner, 2010) and CICO (Everett, Sugai, Fallon, Simonsen, \& O’Keeffe, 2011). It is a common PBIS practice to conduct a Brief FBA to build basic or simple BSPs at the tier 2 level as a systematic and evidence-based technology for assessing the behavior in relation to the context it in which it occurs (Crone \& Horner, 2003). In the case study school, brief FBA/BSP development and implementation involved tier 2 team driven assessments and strategies aimed at students with mild to moderate behavior problems and whose behaviors did not occur in multiple settings. Students who had more complex problems were referred on for tier 3 supports and with more complex behavioral support plans. 
PBIS IN HIGH SCHOOLS

CICO was chosen by the Tier 2 team because it represented an efficient, evidence-based tier 2 intervention designed to help students to learn and demonstrate positive behaviors using positive adult attention and increased performance feedback (Simonsen, Myers, \& Briere, 2011). CICO was considered as an appropriate intervention for youth who were starting to engage in problem behaviors and were unresponsive to both school-wide expectations and good preventive classroom management practices. However, it was not designed for students with more intensive and individualized needs. It was delivered as a group-based intervention, and students checked in daily with a trained CICO coordinator at the start of their day and again near the end of the school day to review the behavioral expectations and set daily goals based on a score card with teachers’ feedback.

The critical features of CICO include increased positive adult attention, a link to schoolwide behavioral goals and expectations, frequent feedback, continuous home-school communication, and positive reinforcement (Crone et al., 2010; Simonsen et al., 2011). CICO a readily available intervention that was implemented across multiple settings by many staff with continuous progress monitoring to help transition students from skill development to selfmanagement. In addition to implementing evidence-based targeted interventions and monitoring of these interventions, the tier 2 team also designed the eligibility criteria and implementation system for youth to receive the tier 3 RENEW intervention.

Students were selected for tier 2 supports based upon specific behavioral and academic indicators established by the tier 2 team including three or more major ODRs within a four week period; five or more unexcused absences in a quarter; two or more class failures in a quarter; five to ten nurse visits in a two week period; six incidents of tardy to a class in a quarter; and/or failure to complete a minimum of $50 \%$ of class assignments in a two week period after initiating 


\section{PBIS IN HIGH SCHOOLS}

parent contact and student conferences. Teachers were encouraged to identify students who exhibited internalizing behaviors not captured by the above stated criteria using criteria such as frequent visits to the nurse or guidance office and lack of homework completion after to multiple student conferences. Accompanying the teacher referrals, faculty were required to document all classroom interventions they utilized to support the student, along with the duration of the attempted intervention(s). This allowed members of the tier 2 team to collaborate and problemsolve with the classroom teacher to identify simple and effective behavioral strategies he or she could deliver to the student, as well as to avoid duplication efforts of interventions. These strategies were monitored by the teacher and team to determine their effectiveness. If the student continued to be non-responsive in a two-week time frame, the tier 2 team would begin formulating a quick hypothesis as to the function of the behavior based on data, and offer other targeted supports along the multi-tiered continuum. The team reviewed data monthly to nominate students for targeted supports.

The tier 2 team was trained by university staff in a brief functional behavioral assessment and behavior support planning approach during the 2010-11 school year and began to design and implement basic function-based plans with a cohort of eighteen students. The first task of the tier 2 team was to train all faculty on function of behavior so staff could effectively implement the behavior support plans and understand behavior in context to the environment. Using resources such as "Building Positive Behavior Support Systems in Schools” by Crone and Horner (2003), the tier 2 team analyzed the available data from referral forms and office discipline data to develop an operational definition of the behavior and then conducted brief interviews with staff using Functional Assessment Checklist for Teachers and Staff (FACTS A \& B). Short student interviews were conducted using Student-Guided Functional Assessment Interview Tool adapted 


\section{PBIS IN HIGH SCHOOLS}

from Reed, Thomas, Sprague, and Horner (1997). From the combined interview data a testable hypothesis describing the problem behaviors, the antecedents and consequences, and the function of behavior was generated. If the team reached consensus about its hypothesis statement and the student fit the criteria of mild to moderate problem behaviors, then a subcommittee within this team created a basic BSP. These team members then met with the referring staff to review the BSP and discuss how to implement the recommended strategies. A follow-up meeting was scheduled to evaluate the effectiveness of the plan.

After conducting more research on evidence-based behavior practices, the tier 2 team decided to implement CICO in order to quickly address the needs of students who were showing the first signs of problem behavior and seeking adult attention. The tier 2 team was trained on the procedures of CICO by the university staff, using resources such as CICO-SWIS readiness checklist and "Responding to Problem Behavior in Schools" by Crone et al. (2010). A CICO coordinator was identified who received further training for the specific role of overseeing implementation and using of the SWIS data system. This coordinator was respected by both students and faculty, had effective communication skills, and was dependable. A rollout to the faculty was delivered by the tier 2 team so teachers would have thorough knowledge of their role in providing positive and corrective feedback during the class period and rating the students' performance on the daily scorecard. Student and family orientation to CICO was also provided by members of the tier 2 team and the CICO coordinator. Once students were enrolled in the intervention, data was monitored bi-monthly.

Tier 3 Implementation. The major elements of the RENEW model include, (a) personal futures planning, (b) individualized school-to-career services including work-based learning, school-based learning, and connecting activities, (c) unconditional service provision and 


\section{PBIS IN HIGH SCHOOLS}

supports, (d) strengths-based service provision, (e) building relationships and linkages in the community (natural supports), (f) flexible resource development and funding, (g) individualized team development, and (h) workplace or career-related mentoring (for a detailed description of the RENEW model, please see Malloy, Drake, Abate, \& Cormier, 2010). Individual data collected for students in RENEW included student academic records, attendance, behavior, and community functioning data.

Students were identified for RENEW tier 3 services by the tier 2/3 team based upon their failure to respond to secondary level supports. Data monitored by the tier $2 / 3$ team showed these students exhibited chronic discipline or truancy issues, or multiple and complex emotional and behavioral needs that extended outside of school. Some of the specific criteria that indicated these students were in need of higher level supports were being off track to graduate due to being significantly behind in credits; repeating a grade level; non-response to tier 2 interventions after six weeks of monitoring with documentation that secondary level interventions were implemented with fidelity; escalating ODRs, with six or more in a four week period and/or five or greater out-of-school or in-school suspensions in a two week period; and a high absenteeism rate reflected by five or more unexcused absences in a quarter.

The university staff provided RENEW services to the first five student participants as an opportunity to demonstrate to school staff how the intervention is delivered and to create buy in. In the fall of 2008, the university staff provided two full days of RENEW Facilitator training to eighteen regular and special education teachers, paraprofessionals, and school counselors. Five of the trained school staff members provided the RENEW intervention to an additional 23 RENEW participants between 2008 and 2012. The university staff supported the facilitators with twice-monthly coaching sessions and reflective supervision meetings throughout the project 


\section{PBIS IN HIGH SCHOOLS}

period. Complete data were available for 25 students who participated in RENEW.

RENEW implementation was monitored by university staff through twice-monthly

observations for at least one youth meeting per quarter using the RENEW procedure manual (Malloy et al., 2012). In addition, the university staff administered an early version of the RENEW fidelity of implementation instrument, the RENEW Integrity Tool or RIT (Malloy \& Drake, 2009). These data were used by the external coach and the school team to assess the level and quality of implementation of the RENEW model.

\section{Data Collection and Analysis}

The UNH Institutional Review Board approved the study, and informed consent was obtained from school officials to use school-level data and de-identified student data. The human subjects approval was obtained for this study, and informed school consent was used for schoollevel data and de-identified student data for tier 2. The demographics of this school reflect many of the high schools in the state. The abundance of schools with similar demographics limits the possibility this school could be identified.

This study was conducted in the real-world high school setting, and thus the data were collected based on availability at each level and each for intervention. While multiple data sources were available for tiers 2 and 3, ODR data were selected as the primary tier 1 outcome measure. ODRs are often used as a measure of PBIS tier 1 outcomes (Spaulding, 2010) and the ODR data for the case study schools appeared to be the most reliable data that were available to measure tier 1 outcomes. Early warning systems (Burke, 2015; Carl, Richardson, Cheng, Kim, \& Meyer, 2013) have used outcomes such as out-of-school suspensions, days absent, unexcused days absent, credit hours earned per in-school suspensions, GPA, and dropout to identify students at risk of failure. Given their connection with screening for tier 2 and 3 supports, these 


\section{PBIS IN HIGH SCHOOLS}

data were selected as outcome measures for interventions beyond tier 1 .

Tier 1 fidelity data. Fidelity of universal PBIS implementation was determined by scores on the School-Wide Evaluation Tool, or SET (Sugai, Lewis-Palmer, Todd, \& Horner, 2005) and the Team Implementation Checklist (TIC). The SET was conducted by university staff in the spring of each year. The SET is an assessment of the school's implementation of seven features of PBIS. Fidelity of implementation is achieved with an overall score of $80 \%$ or greater on the SET, plus a score of $80 \%$ or above on the feature for expectations taught. Descriptive statistics were used to analyze changes over time.

Tier 1 outcome data. The Tier 1 data included annual event dropout rate, ODRs, out-ofschool suspension rates, and in-school suspension rates, collected each summer after final grades were submitted. Discipline outcome data were collected using SWIS twice per year after each semester ended. Dropout rates were collected from the New Hampshire Department of Education's database (2012), calculated as the number of dropouts divided by the number enrolled on October 1 of each year, plus students that dropped out before October 1. Descriptive statistics were used to analyze dropout, out-of-school, and in-school suspension rates. These data indicators were not tested for comparable significance. The Change Point Test (Siegel \& Castellan, 1998), a nonparametric version of regression analysis, which can be used to identify localized changes in the smoothness of a curve, was used to determine if there was a significant change in the slope of the ODR data during the project (Bohanon et al., 2012)

Tier 2 fidelity data. Tier 2 fidelity of implementation was monitored by using the team self-assessment and action planning tool, adapted from the Checklist for Individual Student Systems (CISS) and the Targeted Team Checklist (Anderson et al., 2011; Muscott \& Mann, 2007) twice per year every spring and fall. Descriptive statistics were used to analyze changes in 


\section{PBIS IN HIGH SCHOOLS}

data over time.

Tier 2 outcome data. Tier 2 student-level outcomes were collected by school quarter, including numbers of ODRs, unexcused absences, and suspensions. Number of credits earned for students who received the tier 2 interventions could only be collected by semester (half-year). Overall one-way ANOVA was used to identify significant reductions in these outcomes variables. Post Hoc analysis involved Tukey’s HSD to identify changes in time points.

Tier 3 fidelity data. Components of the TIC were used to track tier 3 supports. The TIC approximates the constructs of the SET and both tools are highly correlated with each other; however, it adds components related to intensive interventions (e.g., team in place, systems in place) (Vincent, Spaulding, \& Tobin, 2010). Fidelity of implementation of the RENEW model was monitored by IOD staff twice per year, but not collected for this study. Descriptive statistics were used to analyze changes in data over time.

Tier 3 outcome data. RENEW student-level data were collected per semester and include ODRs, suspensions, unexcused absences, credits earned, and annual non-cumulative GPA, calculated by assigning values to letter grades according to the school's GPA scale. Many of these factors, particularly unexcused absences and GPA, have been found to be reliable predictors of student graduation (Burke, 2015). Overall one-way ANOVA was used to identify significant reductions in these outcomes variables. Post Hoc analysis involved paired sample ttests to identify changes in time points. Table 1 outlines the training and data collection schedule during the 6 years of the project.

\footnotetext{
$<$ Insert Table 1 here $>$
}

\section{Results}

\section{Fidelity (RQ1)}




\section{PBIS IN HIGH SCHOOLS}

The school achieved fidelity of schoolwide tier 1 PBIS implementation during the second year of implementation, indicated by a score of $80 \%$ or greater on the SET (Horner, et al., 2004). The school's SET scores were 36\% at baseline (2006-07), 83\% in 2007-08, 91\% in 2008-09, $89 \%$ in $2009-10$, $86 \%$ in $2010-11$, and $93 \%$ in $2011-12$. The behavioral expectations taught scores were 0 at baseline (2006-07), 70 in 2007-08, 80 in 2008-09, 90 in 2009-10, 70 in 2010-11, and 90 in 2011-12. The interview components of the SET provided qualitative data relative to how the school staff and students perceived the contextual fit of the tier 1 program. The staff began to indicate satisfaction with the changes in the school, beginning with the spring 2009 SET assessment. The assessment showed that the majority of faculty and students knew the behavioral expectations and had participated in tier 1 teaching events, or "roll outs.” Several teachers who were interviewed stated that there was a positive difference in the school's culture and that there was more consistency and systematic application of discipline within the school.

Based on the CISS and Targeted Team Checklist for tier 2, the team achieved implementation scores of $26 \%$ in fall of $2010,63 \%$ in spring $2011,63 \%$ in fall 2011 , and $87 \%$ in spring 2012, indicating improved implementation of tier 2 supports over time. Scores on the TIC related to tier 3 intervention processes (e.g., team in place, systems in place) indicated that basic components were partially in place during the fall of 2009, and fully in place by the spring of 2011.

\section{Tier 1 Outcomes (RQ2)}

School level data also showed that the annual event dropout rate, ODRs, and out-ofschool suspension rates dropped between the first year of PBIS implementation (2007-08) and the final project year (2011-12). In-school suspension rates increased during the same time period (see Table 2). It is important to note that the state age of compulsory education increased 
PBIS IN HIGH SCHOOLS

from 16 years to 18 years on July 1, 2009, resulting in a reduction in reported dropout rates statewide.

<Insert Table 2 Here>

The average daily number of ODRs per 100 students was 1.34 in 2007-2008, 1.01 in 2008-2009, .85 in 2009-2010, .74 in 2010-2011, and .77 in 2011-2012. The total monthly ODR rate was adjusted for per month, per 100 students, per day to provide a more consistent comparison across time points. A significant change point in ODRs was identified in the month of December 2008 ( $z=3.67, p<.000)$, and was sustained through 2012 (Figure 2).

$<$ Insert Figure 2 here $>$

\section{Tier 2 Outcomes (RQ3)}

Individualized Student Supports. The number of ODRs, suspensions, and unexcused absences were compiled by calendar quarter and credits earned were compiled by semester. Changes in means were compared between baseline (before intervention), the period when behavior support was initiated (time 1), and one and two periods after the intervention was initiated (times 2 and 3). Overall one-way ANOVA showed significant reductions in ODRs (F(3, $66)=5.91, p=.001)$ and in-school suspensions $(F(3,66)=7.65, p<.001)$. Post Hoc comparisons adjusted using Tukey’s HSD showed significant differences in ODRs between baseline and time 2, and baseline and time 3. As shown in Table 3, there were also significant differences for in-school suspensions between baseline and times 2 and 3.

$<$ Insert Table 3 Here $>$

CICO. Changes in means of ODRs, suspensions, unexcused absences, and credits earned were compared between baseline, the quarter when CICO was initiated (time 1), and the two quarters after initiation (times 2 and 3). Overall one-way ANOVA showed significant differences 


\section{PBIS IN HIGH SCHOOLS}

for unexcused absences $(F(3,44)=4.92, p=.005$ (see Table 4). Post Hoc comparisons adjusted using Tukey’s HSD showed the differences are between baseline and times 1, 2, and 3, indicating that students showed immediate improvement as soon as they were enrolled and that improvement was consistent over time (not increasing or decreasing).

$<$ Insert Table 4 Here $>$

\section{Tier 3 Outcomes (RQ4)}

RENEW. Data were compared from the semester before the student began RENEW services (baseline), the first semester when enrolled in RENEW (Time 1) and the semester after enrollment (Time 2). A one-way ANOVA showed no significant difference in ODRs, out-ofschool suspensions, in-school suspensions, credits earned per semester, days absent, or unexcused days absent (see Table 5). Annual GPAs were compared for the year before RENEW (baseline) and the year when enrolled in RENEW (time 1). A paired sample t-test showed a significant increase in mean GPA from baseline $(M=.84, S D-.55)$ to year one in RENEW $(M=$ $1.14, S D=.76), t(24)=-2.16, p=.041$.

\section{$<$ Insert Table 5 here $>$}

A review of individual documents showed that all students who received the RENEW intervention developed uniquely constructed, individualized teams that included school staff, and sixteen of the 25 teams (64\%) also included family and community members, such as probation or child welfare case managers, mental health providers, and residential providers, among others. All 25 students had written action plans targeting goals identified by the youth. Seventeen of the 25 students developed individualized alternative activities to obtain credits, including community- and work-based learning experiences, independent study (identified as Extended Learning Opportunities in New Hampshire), and internships. It is also important to note that only 


\section{PBIS IN HIGH SCHOOLS}

one of the 25 students dropped out of high school (4\%), seventeen students (68\%) graduated with a regular or General Equivalency Diploma (GED), two (8\%) students were on track to graduate in June of 2014, one student was placed out of district, and four (16\%) students moved out of district.

\section{Discussion}

The purpose of this case study was to describe the process and outcomes experienced by one high school that implemented positive behavior practices at all three tiers using the multitiered PBIS framework. This study included a description of practices implemented by the school, and school and student level outcomes pre- and post-intervention, including changes in rates of problem behavior, attendance, dropout rates, and academic performance. The case study high school reached and sustained full implementation of a multi-tiered PBIS framework within 3 years using the APEX PBIS model as the blueprint for staff training, practice selection, and implementation. The school was able to develop and implement a system of universal, targeted, and tertiary supports that provided consistency and that was effective in improving student behavior and engagement. The high school experienced a reduction in ODR rates beginning in 2008. This is similar to other case examples in which increases in fidelity of implementation are associated with decreases in ODR rates (Bohanon et al., 2012).

The results indicate that implementation of tier 1 interventions, through techniques such as the direct teaching of classroom expectations (Simonsen, Fairbanks, Briesch, Myers, \& Sugai, 2008), may be associated with improvements in student behaviors and students' connection with the school (i.e., dropout). While there was an increase in in-school suspensions, the school staff indicated that they intentionally increased their use of in-school instead of out-of-school suspensions to keep students in the building and offer those students opportunities for academic 


\section{PBIS IN HIGH SCHOOLS}

recovery. Based on descriptive data, it appears that the increased number of in school suspensions offsets the number of fewer out-of-school suspensions, a factor that indicates a need to work with teachers to implement positive supports in the classroom to keep students in the instructional environment and to reduce the number of suspensions of any kind.

Implementation of tier 2 behavior practices was associated with improved student attendance and behavioral outcomes. In addition, individualized behavior support plans appeared to have a positive impact on student behavior, a major risk factor related to high school failure. Students in the CICO intervention showed improved school attendance, suggesting that the increase in positive adult attention may have a favorable impact on student motivation to attend school. These results indicate that interventions based on function of behavior and student plans designed around pro-active, positive interactions have the potential to improve student behavior and engagement, and therefore reduce their dropout risk.

The high school staff were able to implement the RENEW tertiary intervention for the highest need students despite the fact that RENEW is time-intensive. The students in RENEW were clearly the highest risk and lowest performing group of those studied, indicated by significant numbers of absences and behavior problems at baseline, and yet only one student in RENEW dropped out during the study period The RENEW intervention improved overall academic performance among some of the most challenged students in the school, indicated by a significant improvement in GPA. Academic performance is found to be a reliable predictor of future student graduation (Burke, 2015). The case study demonstrates that it is possible to organize school resources, particularly staff time, to provide interventions at all three tiers, including an intensive intervention for the most at risk high school students. More research is needed to assess the impact of RENEW on a high school's dropout rate and to further assess the 


\section{PBIS IN HIGH SCHOOLS}

impact of RENEW on student academic performance, engagement, and behavior.

One of the primary challenges to implementation in the school included scheduling time for staff to receive training, consultation, and time to participate as members of tier 1 and the tier2/3 systems teams. Staff needed time over and above their regularly scheduled duties to learn new practices such as CICO or RENEW. This required the school administrators to shift some staff time from existing job responsibilities to allow for the implementation. In addition, there were conflicts between school staff regarding the continued use of reactive and exclusionary disciplines practices and policies and the implementation of positive behavior support strategies. Further, administrative and staff turnover required ongoing training and consultation from year to year to ensure continued implementation. To address these challenges, the external PBIS coaches focused on developing reciprocal working relationships with school team members and staff that provided interventions such as CICO, and adjusted the consultation to better meet the needs of the school staff. Further, the external coaches helped the school to document its systems and practices to provide guidance for new staff. This case study indicates that intensive external coaching contributed to the school's sustained implementation of the PBIS framework and evidence-informed practices at all 3 tiers.

This case example illustrates the importance of multi-tiered implementation, including the power of using evidence-informed tier 2 and tier 3 practices to improve the academic and behavioral outcomes for all students. The case study also illustrates the complexity of PBIS implementation, and how school staff worked together in implementation teams, used data more effectively, and organized resources to meet the diverse needs of all students. It is also possible that implementation of schoolwide PBIS in high schools, with a focus on teaching behavior expectations in a systematic way, may yield better school to career transition outcomes for all 


\section{PBIS IN HIGH SCHOOLS}

students, including those with social, emotional, or behavioral challenges. The multi-tiered framework, with the addition of a tier 2 and tertiary level interventions focused on key noncognitive skills has the potential to offer guidance for replication and more rigorous research in high schools.

\section{Limitations}

Several limitations exist in this study. While the value of the case study method is that it provides "an analysis of the context and processes involved in the phenomenon under study" (Johnston, Leach, \& Liu, 1999, p. 203), it is limited in that the findings may not be generalized to settings and contexts that differ from those of the case study school. The school in this case study is a medium-size public high school with a primarily white student population and so the outcomes illustrated here may not be generalizable to high schools with more diverse populations or different environments (such as a large, urban high school). In addition, caution should be used in generalizing the findings of statistical significance of each intervention given the limited number of cases and limited number of semesters studied. Further, the data used here include several imprecise and contextually dependent measures, such as discipline referral data and suspensions, which are influenced by student-teacher interactions, implicit bias, and the specific factors in the setting (Osher, Bear, Sprague, Doyle, 2010). The case study school received grant funds for a continuous period of 6 years to support its PBIS and RENEW implementation, including training and coaching provided at no cost to the school. Additional work is needed to streamline the model and identify funding streams so the implementation process outlined in this case study can be implemented with the resources that are typically available in high schools.

Despite the fact that training for staff on the tier 2 and RENEW practices was provided 


\section{PBIS IN HIGH SCHOOLS}

according to standardized protocols and project staff provided monthly coaching, modeling, and benchmarking feedback to school staff who were implementing the interventions, the lack of specific RENEW fidelity measures make conclusions about the outcomes of these interventions more tenuous. Finally, without data from a control or comparison school and groups, the results this study do not indicate that the implementation of PBIS caused the reductions in dropout rates or behavior problems, or the improvements in student achievement and engagement.

\section{Future Research}

Future research of the impact of the SWPBIS framework in high schools with comparison sites would contribute to the validity of these findings and help to identify the most effective processes for implementation. Research on the impact of teaching behavior expectations and social skills using the SWPBIS framework may also yield important information about how to make implementation more contextually relevant to the high school context. Further, research is needed to assess whether the intentional implementation of evidence-based tier 2 and tier 3 practices are related to improved student outcomes such as higher students graduation rates, especially for high-need populations such as students with disabilities and African-American students. More intensive studies specific to issues of staff time and other resources needed to learn and implement research-based, positive behavior support practices in high schools at all 3 tiers can contribute to our understanding of how best to plan and manage staff time in schools in order to achieve improved outcomes. Clearly, high school students who are facing significantly more complex academic, social, and developmental, and transitional challenges as they mature need consistency, support, and opportunities for growth no matter what their individual backgrounds or experiences. More rigorous research about positive strategies and implementation frameworks that support their emotional and behavioral growth 
PBIS IN HIGH SCHOOLS

and development into adulthood is critical.

\section{Conclusions}

This case study offers a blueprint for implementation of a multi-tiered framework for positive behavioral support practices at the high school level, and illustrates how implementation of practices at all 3 tiers may result in improved student outcomes, including school dropout, student engagement, behavior problems, and academic progression. The study also illustrates importance of training and PBIS coaching to the fidelity of implementation of each practice being implemented. Youth who have dropout risk factors have some of the worst outcomes of any other subgroup, and yet this case study demonstrated how implementation of tier 2 supports and the RENEW intervention, embedded within the multi-tiered framework, helped to keep highrisk youth engaged in school and on track for graduation. The continued implementation and innovative adaptations of PBIS in high schools is important and should be encouraged, supported, and assessed as a model for improving school outcomes and the transition to adult life for all youth. 


\section{PBIS IN HIGH SCHOOLS}

\section{References}

American Civil Liberties Union. (2008). Talking points: The school to prison pipeline. Retrieved from http://www.aclu.org/racial-justice/school-prison-pipeline-talking-points

Anderson, C. M., Lewis-Palmer, T., Todd, A. W., Horner, R. H., Sugai, G., \& Sampson, N. K. (2011). Individual Student Systems Evaluation Tool, Version 2.8. Eugene: University of Oregon, Educational and Community Supports. Retrieved from http://www.pbis.org/common/pbisresources/tools/ISSET_TOOL_v2.8_February_2011.pd $\mathrm{f}$

Balfanz, R., Herzog, L., \& Mac Iver, D. J. (2007). Preventing student disengagement and keeping students on the graduation path in urban middle-grades schools: Early identification and effective interventions. Educational Psychologist, 42(4), 223-235. doi: $10.1080 / 00461520701621079$

Bohanon, H. (2015). Changes in adult behavior to decrease disruption from students in nonclassroom settings. Intervention in School and Clinic, 15 (1), 12-18. Retrieved from http://ecommons.luc.edu/education_facpubs/39

Bohanon, H., Fenning, P., Hicks, K., Weber, S., Their, K., Akins. B., ... McArdle, L. (2012). Case example of the implementation of schoolwide positive behavior support in a high school setting. Preventing School Failure, 56 (2), 92-103. doi:

10.1080/1045988X.2011.588973

Bohanon, H., Gilman, C., Parker, B., Amell, C., \& Sortino, G. (2016 online first). Using school improvement and implementation science to integrate multi-tiered systems of support in secondary schools. Australasia Journal of Special Education. pp. 1-18. doi:

10.1017/jse.2016.8. http://ecommons.luc.edu/education_facpubs/80/ 


\section{PBIS IN HIGH SCHOOLS}

Bohanon, H. \& Wu, M. (2014). Developing buy-in for positive behavior support in secondary settings. Preventing School Failure, 58 (4), 1-7. doi: 10.1080/1045988X.2013.798774 http://ecommons.luc.edu/education_facpubs/17/

Bradshaw, C. P., Mitchell, M. M., \& Leaf, P. J. (2010). Examining the effects of School-Wide Positive Behavioral Interventions and Supports on student outcomes: Results from a randomized controlled effectiveness trial in elementary schools. Journal of Positive Behavior Interventions, 12, 133-148. doi:10.1177/1098300709334798

Bradshaw, C. P., Pas, E. T., Debnam, K. J., \& Johnson, S. L. (2015). A focus on implementation of Positive Behavioral Interventions and Supports (PBIS) in high schools: Associations with bullying and other indicators of school disorder. School Psychology Review, 44(4), 480-498. Retrieved from http://www.nasp.org

Bradshaw, C., Reinke, W., Brown, L., Bevans, K., \& Leaf, P. (2008). Implementation of schoolwide positive behavioral interventions and supports (PBIS) in elementary schools: Observations from a randomized trial. Education and Treatment of Children, 31, 1-26. Retrieved from http://www.jstor.org/stable/42899960

Bradshaw, C. P., Waasdorp, T. E., Debnam, K. J., \& Johnson, S. L. (2014). Measuring school climate in high schools: A focus on safety, engagement, and the environment. Journal of School Health, 84(9), 593-604. doi:10.1111/josh.12186

Brownstein, R. (2009). Pushed out. Teaching Tolerance, 36. Southern Poverty Law Center. Retrieved from: http://www.tolerance.org/print/magazine/number-36-fall2009/feature/pushed-out

Burke, A. (2015). Early identification of high school graduation outcomes in Oregon leadership network schools. REL 2015-079. Regional Educational Laboratory Northwest. 


\section{PBIS IN HIGH SCHOOLS}

Carl, B., Richardson, J. T., Cheng, E., Kim, H., \& Meyer, R. H. (2013). Theory and application of early warning systems for high school and beyond. Journal of Education for Students Placed at Risk, 18(1), 29-49. doi:10.1080/10824669.2013.745374

Carter, E. W., Lane, K. L., Pierson, M., \& Glaeser, B. (2006). Self-determination skills of transition-age youth with emotional disturbances and learning disabilities. Exceptional Children, 72, 333-346. doi: 10.1177/001440290607200305

Childs, K. E., Kincaid, D., George, H. P., \& Gage, N. A. (2016). The relationship between school-wide implementation of Positive Behavior Intervention and Supports and student discipline outcomes. Journal of Positive Behavior Interventions, 18(2), 89-99. doi:10.1177/1098300715590398

Crone, D., Hawken, L., \& Horner, R. (2010). Responding to problem behavior in schools, Second Edition: The Behavior Education Program. The Guilford Practical Intervention in the Schools Series. New York: Guilford Press.

Crone, D. A., \& Horner, R. H. (2003). Building positive behavior support systems in schools. New York, London: Guilford Press.

Debnam, K. J., Pas, E. T., \& Bradshaw, C. P. (2012). Interventions and supports: A preliminary descriptive analysis. Journal of Positive Behavior Interventions, 14(3), 142-152. doi: $10.1177 / 1098300712436844$

Duncan, A. (March 8, 2010). Crossing the Next Bridge, Remarks of the U.S. Secretary of Education, Selma, Alabama: U.S. Department of Education. Retrieved December 10, 2010. Retrieved from http://www2.ed.gov/news/speeches/2010/03/03082010.html

Educational and Community Supports. (2010). Patterns of Office Discipline Referrals. Retrieved from http://www.uoecs.org/ 


\section{PBIS IN HIGH SCHOOLS}

Eagle, J. W., Dowd-Eagle, S. E., Snyder, A., \& Holtzman, E. G. (2015). Implementing a MultiTiered System of Support (MTSS): Collaboration between school psychologists and administrators to promote systems-level change. Journal of Educational \& Psychological Consultation, 25(2/3), 160-177. doi:10.1080/10474412.2014.929960

Everett, S., Sugai, G., Fallon, L., Simonsen, B., \& O’Keeffe, B. (2011). School-wide tier 2 interventions: Check-In Check-Out getting started workbook. OSEP Center on Positive Behavioral Interventions and Supports Center for Behavioral Education and Research, University of Connecticut.

Farrington, C.A., Roderick, M., Allensworth, E., Nagaoka, J., Keyes, T.S., Johnson, D.W., \& Beechum, N.O. (2012)._Teaching adolescents to become learners. The role of noncognitive factors in shaping school performance:_A critical literature review. Chicago: University of Chicago Consortium on Chicago School Research.

Fixsen, D. L., Blasé, K. A., Timbers, G. D., \& Wolf, M. M. (2007). In search of program implementation: 792 replications of the Teaching-Family Model. The Behavior Analyst Today, 8(1), 96-110. doi: 10.1037/h0100104

Fixsen, D. L., Naoom, S. F., Blase, K. A., Friedman, R. M., \& Wallace, F. (2005). Implementation research: A synthesis of the literature. Tampa, FL: Florida Mental Health Institute, National Implementation Research Network.

Flannery, B. K., Frank, J., Kato, M., Doren, B., \& Fenning, P. (2013). Implementing school-wide positive behavior support in high school settings: Analysis of eight high schools. The High School Journal, 96, 267-282.

Flannery, K. B., Fenning, P., Kato, M. M., McIntosh, K. (2014). Effects of school-wide positive behavioral interventions and supports and fidelity of implementation on problem 


\section{PBIS IN HIGH SCHOOLS}

behavior in high schools. School Psychology Quarterly, Vol 29(2), Jun 2014, 111124. $\underline{\text { doi.org } / 10.1037 / \mathrm{spq} 0000039}$

Flannery, B. K., Guest, E., \& Horner, R. (2010). SWPBS: Schoolwide positive behavior supports. Principal Leadership, 11(1), 38-43. Retrieved from http://www.principals.org

Flannery, B. K., Sugai, G., \& Anderson, C. M. (2009). School-wide positive behavior support in high school: Early lessons learned. Journal of Positive Behavior Interventions, 11(3), 177-185. doi: 0.1177/1098300708316257

Forman, S. G., \& Crystal, C. D. (2015). Systems consultation for multitiered systems of supports (MTSS): Implementation issues. Journal of Educational \& Psychological Consultation, 25(2/3), 276-285. doi:10.1080/10474412.2014.963226

Freeman, J., Simonsen, B., McCoach, D. B., Sugai, G., Lombardi, A., \& Horner, R. (2016). Relationship between School-Wide Positive Behavior Interventions and Supports and academic, attendance, and behavior outcomes in high schools. Journal of Positive Behavior Interventions, 18(1), 41-51. doi:10.1177/1098300715580992Hammond, C.,

Hammond, C., Linton, D., Smink, J., \& Drew, S. (2007). Dropout risk factors and exemplary programs. National Dropout Prevention Center, Communities In Schools, Inc. Retrieved from http://www.apa.org/pi/families/resources/school-dropout-prevention.pdf

Horner, R. (2014, September). Using positive behavioral interventions and supports to make schools more effective and equitable. Positive behavior for learning conference. Hamilton, New Zealand. Retrieved from: http//:www.pbis.org/presentations.

Horner, R. H., \& Sugai, G. (2005). School-wide positive behavior support: An alternative approach to discipline in schools. In L. Bambara \& L. Kern (Eds.), Positive Behavior Support (pp. 359-390). New York, NY: Guilford Press. 


\section{PBIS IN HIGH SCHOOLS}

Horner, R. H., Sugai, G., \& Anderson, C. M. (2010). Examining the evidence base for schoolwide positive behavior support. Focus on Exceptionality, 42(8), 1-14.

Horner, R., Sugai, G., Smolkowski, K., Eber, L., Nakasato, J., Todd, A., \& Esperanza, J. (2009). A randomized, wait-list controlled effectiveness trial assessing school-wide positive behavior support in elementary schools. Journal of Positive Behavior Interventions, 11, 133-145.

Horner, R. H., Sugai, G., Todd, A. W., \& Lewis-Palmer, T. (2005). School-wide positive behavior support. In L. Bambara \& L. Kern (Eds.), Individualized supports for students with problem behaviors: Designing positive behavior plans (pp. 359-390). New York: Guilford Press.

Johnston, W. J., Leach M. P., \& Liu, A. H. (1999). Theory testing using case studies in businessto-business research. Industrial Marketing Management 28, 201-213.

Journal of Educational and Psychological Consultation, Aims and Scope. (2017). Retrieved from:

http://tandfonline.com/action/journalInformation?show=aimsScope\&journalCode=hepc2 0

Kincaid, D., Dunlap, G., Kern, L., Lane, K. L., Bambara, L. M., Brown, F., .. Knoster, T. P. (2016). Positive Behavior Support: A Proposal for Updating and Refining the Definition. Journal of Positive Behavior Interventions, 18(2), 69-73. doi:10.1177/1098300715604826

Lane, K. L., Wehby, J. H., Robertson, E. J., \& Rogers, L. A. (2007). How do different types of high school students respond to schoolwide positive behavior support programs? Characteristics and responsiveness of teacher-identified students. Journal of Emotional 
PBIS IN HIGH SCHOOLS

and Behavioral Disorders, 15(1), 3-20. doi: 10.1177/10634266070150010201

Lassen, S., Steele, M., \& Sailor, W. (2006). The relationship of school-wide positive behavior support to academic achievement in an urban middle school. Psychology in Schools 43, 701-712.

Lohrmann, S., Martin, S. D., \& Patil, S. (2013). External and internal coaches' perspectives about overcoming barriers to universal interventions. Journal of Positive Behavior Interventions, 15(1), 26-38. doi:0.1177/1098300712459078

Losen, D., \& Gillespie, J. (2012). Opportunities suspended: The disparate impact of disciplinary exclusion from school. The Civil Rights Project. Los Angeles, CA. Retrieved from: http://civilrightsproject.ucla.edu/resources/projects/center-for-civil-rightsremedies/school-to-prison-folder/federal-reports/upcoming-ccrr-researchLosen, D., Hodson, C., Keith, M. A., Morrison, K, \& Belway, S. (2015). Are we closing the discipline gap? The Civil Rights Project. Los Angeles, CA. Retrieved from https://civilrightsproject.ucla.edu/resources/projects/center-for-civil-rightsremedies/school-to-prison-folder/federal-reports/are-we-closing-the-school-disciplinegap/AreWeClosingTheSchoolDisciplineGap_FINAL221.pdf

Losen, D., \& Skiba, R. (2010). Suspended education: Urban middle schools in crisis. Southern Poverty Law Center. Retrieved from http://civilrightsproject.ucla.edu/research/k-12education/school-discipline/suspended-education-urban-middle-schools-incrisis/Suspended-Education_FINAL-2.pdf

Malloy, J. M., \& Drake, J. (2012). RENEW Implementation Checklist (RIC). University of New Hampshire, Durham.

Malloy, J. M., Drake, J., Abate, K., \& Cormier, G. M. (2010). The RENEW model of futures 


\section{PBIS IN HIGH SCHOOLS}

planning, resource developments, and school-to-career experiences for youth with emotional and behavioral disorders, in In D. Cheney (Ed.), Transition of secondary students with emotional and behavioral disabilities (pp. 267-304). Reston, VA: Council for Exceptional Children.

Malloy, J., Drake, J., Cloutier, \& Couture, D. (2012). RENEW Facilitator's Training Manual. The Institute on Disability, University of New Hampshire: Durham.

May, S., Ard, W., Todd, A. W., Horner, R. H., Glasgow, A., Sugai, G., and Sprague, J. R. (2006). School-wide information system. Eugene: University of Oregon, Educational and Community Supports.

McIntosh, K., Chard, D., Boland, J., \& Horner, R. H. (2006). Demonstration of combined efforts in school-wide academic and behavioral systems and incidence of reading and behavior challenges in early elementary grades. Journal of Positive Behavior Interventions, 8, $146-154$.

McIntosh, K., Filter, K. J., Bennett, J., Ryan, C., \& Sugai, G. (2010). Principles of sustainable prevention: Designing scale-up of school-wide positive behavior support to promote durable systems. Psychology in the Schools, 47, 5-21.

Murphey, D., Stratford, B., Gooze, R., Bringewatt, E. P., Cooper, M., Carney, R. \& and Rojas, A. (2014). Are the children well? A model and recommendations for promoting the mental wellness of the nation's young people. Child Trends Report. Robert Wood Johnson Foundation: Washington.

Muscott, H. \& Mann, E. (2007). Functional behavioral assessment implementation and behavioral support plan self-assessment. NH Center for Effective Behavioral Interventions and Supports, Bedford, $\mathrm{NH}$. 


\section{PBIS IN HIGH SCHOOLS}

New Hampshire Department of Education, (2006). Assessment and AYP reports. Retrieved from http://my.doe.nh.gov/profiles/

New Hampshire Department of Education, (2013). NH school and district profiles. Retrieved from http://my.doe.nh.gov/profiles/

Newman, L., Wagner, M., Cameto, R., Knokey, A. M. (2009). The post-high school outcomes of youth with disabilities up to 4 years after high school. A Report from the National Longitudinal Transition Study-2 (NLTS2) (NCSER 2009-3017). Menlo Park, CA: SRI International.

Newman, L., Wagner, M., Knokey, A.-M., Marder, C., Nagle, K., Shaver, D., Wei, X., with Cameto, R., Contreras, E., Ferguson, K., Greene, S., and Schwarting, M. (2011). The post-high school outcomes of young adults with disabilities up to 8 years after high school. A report from the National Longitudinal Transition Study-2 (NLTS2). NCSER 2011-3005. Menlo Park, CA: SRI International. Downloaded on December 28, 2013 Retrieved from http://www.nlts2.org/reports/

OSEP Technical Assistance Center on Positive Behavioral Interventions and Supports (October 2015). Positive Behavioral Interventions and Supports (PBIS) Implementation Blueprint: Part 1 - Foundations and Supporting Information. Eugene, OR: University of Oregon. Retrieved from www.pbis.org.

Osher, D., Bear, G. G., Sprague, J. R., \& Doyle, W. (2010). How can we improve school discipline? Educational Researcher, 39(1), 48-58.

Pellerin, L. A. (2005). Student disengagement and the socialization styles of high schools. Social Forces, 84(2), 1159-1179.

Reed, H., Thomas, E., Sprague, J. R., \& Horner, R. H. (1997). The student guided functional 


\section{PBIS IN HIGH SCHOOLS}

assessment interview: An analysis of student and teacher agreement. Journal of Behavioral Education, 7(1), 33-49. doi: 10.1023/A:1022837319739

Sadler, C., \& Sugai, G. (2009). Effective behavior and instructional support: A district model for early identification and prevention of reading and behavior problems. Journal of Positive Behavior Interventions, 11, 35-46.

Scott, T. M. (2001). A schoolwide example of positive behavioral support. Journal of Positive Behavior Interventions, 3(2), 88-94.

Siegel, S., \& Castellan, N. J. (1998). Nonparametric statistics for the behavioral sciences. New York, NY: McGraw-Hill.

Simonsen, B., Fairbanks, S., Briesch, A., Myers, D., \& Sugai, G. (2008). Evidence-based practices in classroom management: Considerations for research to practice. Education \& Treatment of Children, 31(3), 351-380. doi:10.1353/etc.0.0007

Simonsen, B., Myers, D., \& Briere, D. E. (2011). Comparing a behavioral check-in/check-out (CICO) intervention to standard practice in an urban middle school setting using an experimental group design. Journal of Positive Behavior Interventions, 13(1), 31-48. doi:10.1177/1098300709359026

Skiba, R. \& Peterson, R. (2000). School discipline at a crossroads: From zero tolerance to early response. Exceptional Children, 32, 200-216.

Spaulding, S. A. (2010). Schoolwide social-behavioral climate, student problem behavior, and related administrative decisions: Empirical patterns from 1,510 schools nationwide. Journal of Positive Behavior Interventions, 12(2), 69-85. doi:10.1177/1098300708329011

Stewart, E. A. (2003). School social bonds, school climate, and school misbehavior: A multilevel 
PBIS IN HIGH SCHOOLS

analysis, Justice Quarterly, 20(3), 575-604.

Stewart, R. M., Benner, R. M., Martella, R. M. \& Marchand-Martella, N. E. (2007). Three-tier models of reading and behavior, Journal of Positive Interventions, 9(4), 239-253.

Stolbach, B.C. (2007). Developmental trauma disorder: a new diagnosis for children affected by complex trauma. International Society for the Study of Trauma and Dissociation News, 25(6): 4-6.

Sugai, G. M. (2002) School-wide Positive Behavior Supports: Achieving and Sustaining Effective Learning Environments for All Students. Washington, DC: Testimony submitted April 21, 2002 to the Senate Committee on Health, Education, Labor, and Pensions.

Sugai, G., Horner, R. H., Algozzine, R., Barrett, S., Lewis, T., Anderson, C., . . Simonsen, B. (2010). School-wide positive behavior support: Implementers’ blueprint and selfassessment. In. Eugene, OR: University of Oregon.

Sugai, G., Lewis-Palmer, T., Todd, A., \& Horner, R. (2005). School-wide evaluation tool version 2.1. Eugene: Educational and Community Supports, College of Education, University of Oregon.

Tyre, A. D., \& Feuerborn, L. L. (2016). The minority report: The concerns of staff opposed to schoolwide positive behavior interventions and supports in their schools. Journal of Educational and Psychological Consultation, 27(2), 1-28. doi:10.1080/10474412.2016.1235977

U.S. Department of Education. (2016, December). Children identified with or at risk for an emotional disturbance topic area intervention report: Functional behavioral assessmentbased interventions. Retrieved from http://whatworks.ed.gov

U.S. Department of Education. (2012). The transformed Civil Rights data collection: Revealing 
PBIS IN HIGH SCHOOLS

new truths about our nation's schools. Washington, DC: Office of Civil Rights.

Vincent, C. G., Randall, C., Cartledge, G., Tobin, T. J., \& Swain-Bradway, J. (2011). Toward a conceptual integration of cultural responsiveness and schoolwide positive behavior support. Journal of Positive Behavioral Interventions, 13(4), 219-229.

Vincent, C., Spaulding, S., \& Tobin, T. J. (2010). A Reexamination of the Psychometric Properties of the School-Wide Evaluation Tool (SET). Journal of Positive Behavior Interventions, 12(3), 161-179. doi: 10.1177/1098300709332345

Wagner, M. \& Cameto, R. (2004). The characteristics, experiences, and outcomes of youth with emotional disturbances. NLTS2 Data Brief, 3, 2. Retrieved from http://www.ncset.org/publications/viewdesc.asp?id=1687

Wagner, M. \& Davis, M. (2006). How are we preparing students with emotional disturbances for the transition to young adulthood? Findings from the National Longitudinal Transition Study, Journal of Emotional and Behavioral Disorders, 14(2), 86-98.

Wagner, M. Kutash, K., Duchnowski, A.J., Epstein, M. H., \& Sumi, W. C. (2005). The children and youth we serve: A national picture of the characteristics of students with emotional disturbances receiving special education. Journal of Emotional and Behavioral Disorders, 13(2), 70-86. doi: 10.1177/106334266050130020201

Way, N., Reddy, R., \& Rhodes, J. (2007). Students’ perceptions of school climate during the middle school years: Associations with trajectories of psychological and behavioral adjustment. American Journal of Community Psychology, 40, 194-213.

Zins, J. E., Weissberg, R. P., Wang, M. C., \& Walberg, H. J. (Eds.). (2004). Building academic success on social and emotional learning: What does the research say? New York: Teachers College Press. 
PBIS IN HIGH SCHOOLS

Table 1

Schoolwide Universal Implementation and Outcome Data

\begin{tabular}{|c|c|c|c|c|c|c|c|}
\hline YEAR & 2006-07 & $\begin{array}{c}\text { 2007-08 } \\
\text { Baseline } \\
\text { Year }\end{array}$ & $\begin{array}{c}2008- \\
09\end{array}$ & $\begin{array}{c}2009- \\
2010\end{array}$ & $2010-11$ & 2011-12 & $\begin{array}{c}\text { Change } \\
\text { Baseline } \\
\text { to } 2012\end{array}$ \\
\hline $\begin{array}{l}\text { SET Scores } \\
\text { (Overall/Expectati } \\
\text { ons Taught) }\end{array}$ & $36 / 0$ & $83 / 70$ & $91 / 80$ & $89 / 90$ & $86 / 70$ & $93 / 75$ & $+10 / 5$ \\
\hline $\begin{array}{l}\text { Number of major } \\
\text { ODRS/100 } \\
\text { Students }\end{array}$ & 101 & 260 & 198 & 152 & 117 & 146 & -114 \\
\hline $\begin{array}{l}\text { Number of In- } \\
\text { School } \\
\text { Suspensions/100 } \\
\text { Students }\end{array}$ & $\mathrm{N} / \mathrm{A}$ & 29.89 & 59.00 & 49.83 & 36.86 & 50.86 & +20.97 \\
\hline $\begin{array}{l}\text { Number of Out-of- } \\
\text { School } \\
\text { Suspensions/100 } \\
\text { Students }\end{array}$ & $\mathrm{N} / \mathrm{A}$ & 46.63 & 34.00 & 31.50 & 31.39 & 24.57 & -22.06 \\
\hline $\begin{array}{l}\text { Annual Event } \\
\text { Dropout Rate- } \\
\text { Case School }\end{array}$ & 3.7 & 2.8 & 2.1 & 1.39 & .88 & .88 & -1.92 \\
\hline $\begin{array}{l}\text { Annual Event } \\
\text { Dropout Rate- } \\
\text { State }\end{array}$ & 3.2 & 2.5 & 1.7 & .97 & 1.19 & 1.26 & -1.24 \\
\hline
\end{tabular}


PBIS IN HIGH SCHOOLS

Table 2

Outcomes of Students with Behavior Support Plans Over Four Semesters $(n=18)$

\begin{tabular}{lrrrc}
\hline Outcome Variables & Baseline & Time 1 & Time 2 & Time 3 \\
\hline Credits Earned & 2.64 & 2.64 & 1.67 & 2.43 \\
ODRs & 3.83 & 2.11 & $0.67^{* *}$ & $0.56^{* *}$ \\
Unexcused Absences & 2.47 & 2.60 & 2.73 & 2.31 \\
ISS & 1.39 & 0.72 & $0.22^{* *}$ & $0.11^{* *}$ \\
OSS & 0.67 & 0.28 & 0.12 & 0.06
\end{tabular}

**Significant change in

means from baseline: $p<.01$ 
PBIS IN HIGH SCHOOLS

Table 3

Outcomes of Students in Check In/Check Out Over Four Semesters (n=13)

\begin{tabular}{lcccc}
\hline \multicolumn{1}{c}{ Outcome Variables } & Baseline & Time 1 & Time 2 & Time 3 \\
\hline Credits Earned & 2.08 & 2.44 & 2.71 & 3 \\
ODRs & 2.23 & 1 & 2.09 & 1.45 \\
Unexcused Absences & 8.46 & $3.85^{*}$ & $3.91^{*}$ & $2.45^{*}$ \\
ISS & 1.38 & .38 & 1.2 & 0.4 \\
OSS & .69 & .31 & 0.6 & 0.3 \\
\hline
\end{tabular}

*Significant change in means from baseline: $p<.05$ 
PBIS IN HIGH SCHOOLS

Figure 1

APEX High School Continuum of Supports Model

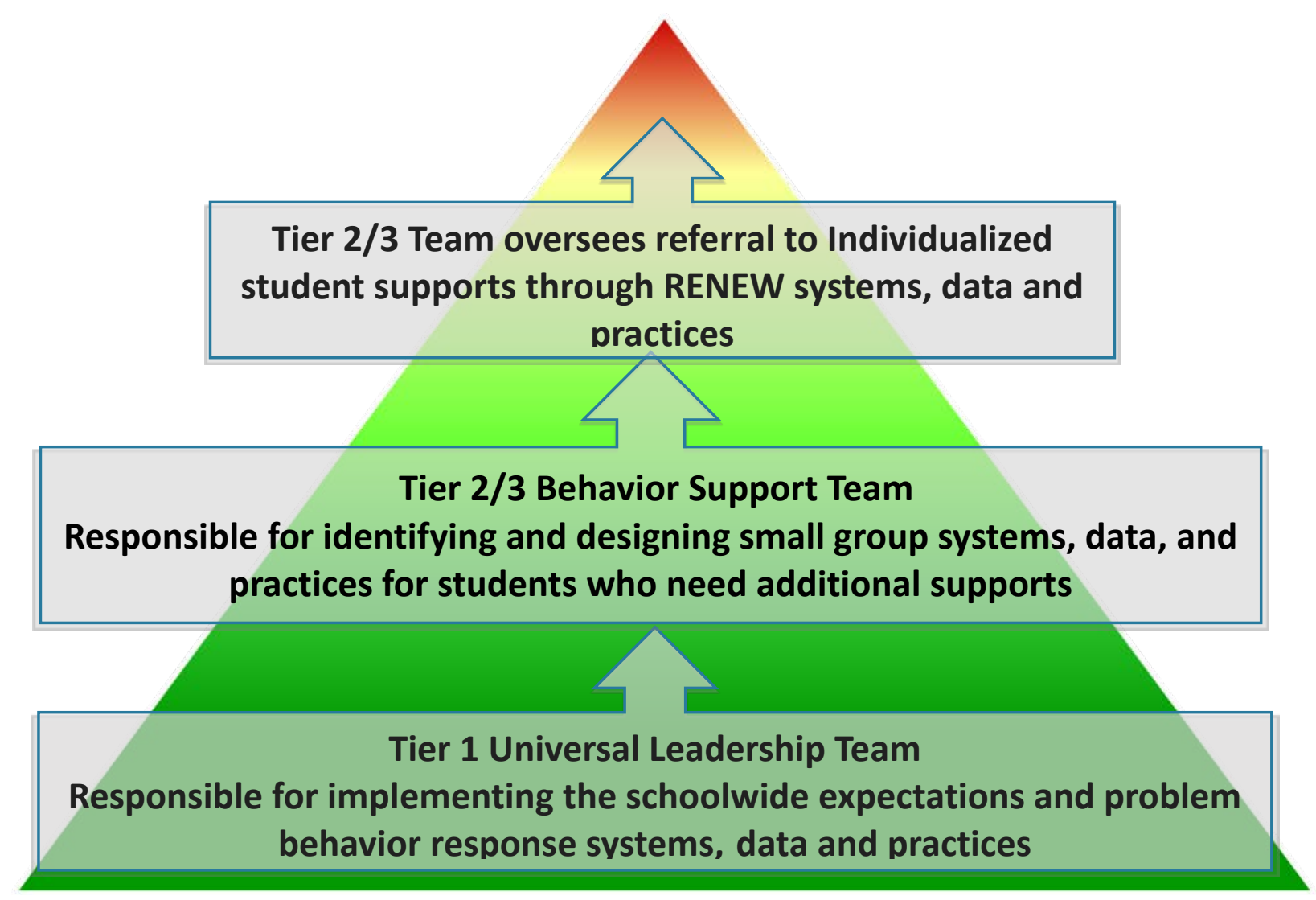

Depiction of how PBIS multi-tiered model of supports was organized 
PBIS IN HIGH SCHOOLS

Figure 2

ODRS per 100 Students per Month

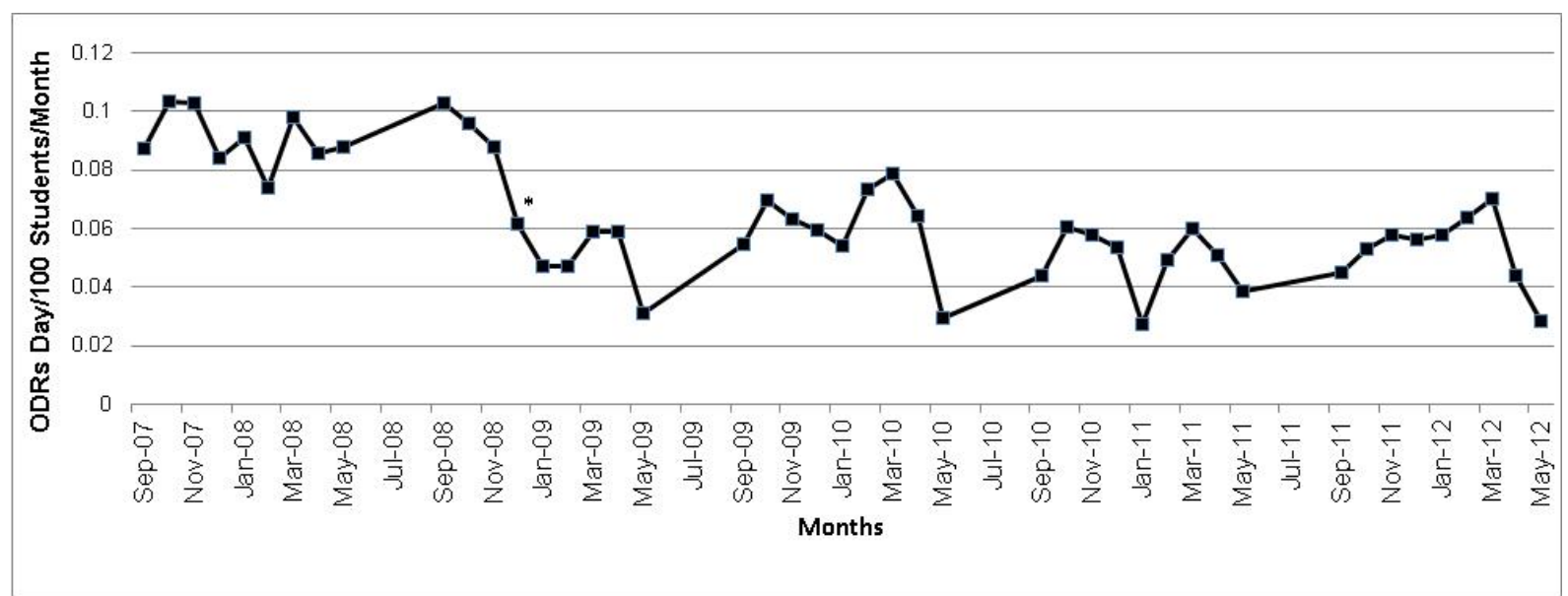

Changes of bi-monthly ODR rates data over time, showing a significant reduction beginning in December $2008\left({ }^{*} z=3.67, p<.000\right)$. 